\section{Osteochondritis Dissecans in Pediatric Patients with Juvenile Idiopathic Arthritis}

To the Editor:

Joint pain and swelling are common symptoms of patients with juvenile idiopathic arthritis (JIA) with active joint inflammation. When patients with JIA have persistent pain or mechanical symptoms despite treatment of their inflammation, other causes must be considered.

Osteochondritis dissecans (OCD) is a focal alteration of subchondral bone formation that causes softening of the overlying cartilage, which can progress to instability, eventual osteochondral detachment, and early osteoarthritis ${ }^{1}$. Poorly localized knee pain with activity is common in early OCD lesions, and progresses to swelling, catching, or locking as the lesion becomes unstable ${ }^{1}$. The incidence in the general population is 9.5-29/100,000, occurring 2-3.8 times more frequently in males than females ${ }^{1,2,3}$. The most commonly affected joint is the knee ${ }^{1}$. Fifty-one to $69 \%$ of knee lesions affect the medial femoral condyle (MFC), and $16.5-33 \%$ affect the lateral femoral condyle (LFC) $)^{1,2,3}$. First-line management is conservative, with $33.5 \%$ requiring surgical intervention ${ }^{4}$. Multiple theories regarding the etiology of OCD lesions have been proposed, including repetitive microtrauma, focal ischemia, and genetic predisposition $^{1}$. König initially theorized an inflammatory etiology when coining the term osteochondritis dissecans ${ }^{5}$. Despite major advances in the understanding of OCD, many issues regarding its pathophysiology remain unresolved ${ }^{6}$.

Our study has received the approval of the Western Research Ethics Board and Lawson Research Ethics Board (approval number R-19-269). Informed telephone consent was obtained from each patient or his or her substitute decision maker. The Western Research Ethics Board waived the requirement for written consent on the basis that many of the patients attend in-person hospital visits infrequently.

We identified 10 patients between January 2010 and June 2018 with JIA who were found to have OCD as the cause of knee pain and mechanical issues. During this period our clinic saw 20-25 new cases of JIA per year.

Table 1 describes the clinical characteristics of patients with concomitant JIA and OCD. Nine of the patients were female. The mean age of patients at the time of JIA diagnosis was $6.16 \pm 3.74$ years $($ mean \pm SD). There were 2 patients with psoriatic, 3 oligoarticular, 1 extended oligoarticular, 3 polyarticular arthritis, and 1 patient with systemic JIA. Eight of 10 patients received methotrexate at some point during their treatment. Four patients received biologics. Of these, 3 initially received a tumor necrosis factor- $\alpha$ inhibitor (adalimumab, infliximab, or etanercept), and the third, with systemic JIA, initially received anakinra.

Table 2 describes the characteristics of OCD lesions. All patients had knee radiographs followed by magnetic resonance imaging (MRI). Indications for imaging were persistent or focal pain, catching or locking, or trauma. Six patients had lesions involving the right knee, and 4 had lesions involving the left knee. Four lesions involved the MFC, 4 involved the LFC, and 2 involved the patella.

The mean age of patients at the time of diagnosis with OCD was 10.85 \pm 1.74 years (mean $\pm \mathrm{SD}$ ). The mean interval between JIA and OCD diagnosis was $4.69 \pm 4.50$ years (mean $\pm \mathrm{SD}$ ). All patients had JIA-related disease activity in the joint affected by OCD. Three patients had an existing OCD lesion at the time of JIA diagnosis. All 7 patients with JIA onset prior to the diagnosis of $\mathrm{OCD}$ received intraarticular glucocorticoid injections of the joint subsequently affected by OCD. The number of joint injections varied between 1 and 5. Patients 2 and 7 reported previous minor falls onto the subsequently affected knee, and patient 10 had OCD identified during imaging following a kick to the flexed knee during a soccer game. Four patients without mechanical symptoms underwent nonoperative management with rest and activity modification, including avoidance of high-impact sports and repetitive load-bearing activities. Six patients with locking or worsening pain underwent arthroscopic examination. Of these, 5 lesions were debrided, 1 was microfractured, and 1 received transarticular drilling. Outcomes are listed in Table 2.

In patients with JIA who have persistent or focal joint pain, or atypical symptoms such as catching or locking, alternative diagnoses such as OCD should be considered, particularly when these symptoms are present while inflammatory disease is clinically inactive. Imaging with radiographs and MRI can help clarify the diagnosis. In contrast to previous epidemiologic studies, this population was mostly female; the distribution of lesions was atypical (the LFC was affected as often as the MFC, and 2 patellar lesions were identified); and $50 \%$ of the patients required surgical management. The atypical sex and anatomic distributions are in agreement with previous studies by Kröger, et $a l^{7}$ and Kubo, et $a l^{8}$.

The etiology of OCD in patients with JIA compared with healthy children affected with OCD may be different. Persistent synovitis may increase the risk of cartilage damage ${ }^{9}$ and the development of OCD; glucocorticoid injections may affect the risk of developing OCD through effects on cartilage metabolism ${ }^{10}$ and mechanical disruption of the articular surface; and altered gait biomechanics related to joint pain may change load distribution in joints affected by JIA. Further prospective studies are needed to

Table 1. Demographics and clinical characteristics of patients with JIA and OCD.

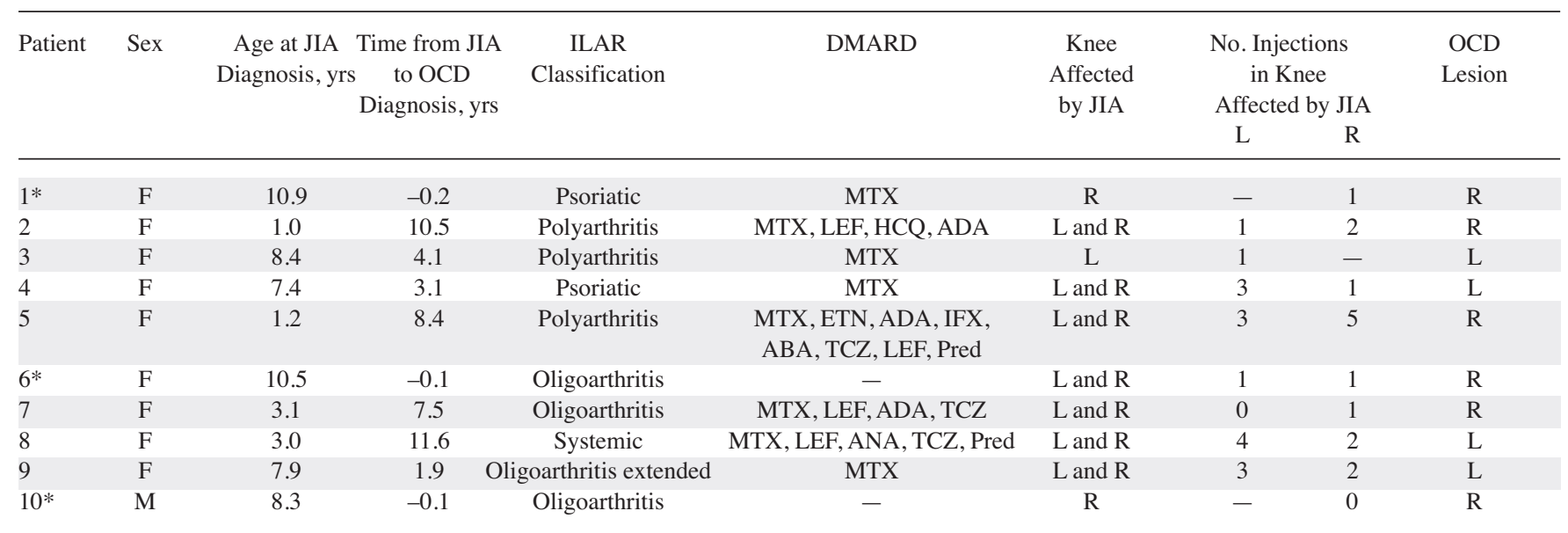

* OCD lesion present at the time of JIA diagnosis. JIA: juvenile idiopathic arthritis; OCD: osteochondritis dissecans; ILAR: International League of Associations for Rheumatology; DMARD: disease-modifying antirheumatic drugs; MTX: methotrexate; LEF: leflunomide; HCQ: hydroxychloroquine; ADA: adalimumab; IFX: infliximab; ABA: abatacept; TCZ: tocilizumab; ETN: etanercept; Pred: prednisone; ANA: anakinra. 
Table 2. Characteristics of OCD lesions in patients with JIA.

\begin{tabular}{|c|c|c|c|c|c|}
\hline Patient & $\begin{array}{l}\text { Age at OCD } \\
\text { Diagnosis, yrs }\end{array}$ & $\begin{array}{l}\text { OCD Lesion } \\
\text { Location }\end{array}$ & $\begin{array}{l}\text { Previous Injury } \\
\text { of Affected Joint }\end{array}$ & Surgery & Outcome \\
\hline $1 *$ & 10.7 & R LFC & No & $\begin{array}{l}\mathrm{R} \text { knee debridement and } \\
\text { transarticular drilling }\end{array}$ & $\begin{array}{l}\text { Ongoing mechanical } \\
\text { symptoms and pain }\end{array}$ \\
\hline 2 & 11.5 & R LFC & $\begin{array}{c}\text { Fall on R knee while } \\
\text { playing as a hockey goalie }\end{array}$ & $\begin{array}{l}\mathrm{R} \text { knee debridement } \\
\text { and microfracturing }\end{array}$ & $\begin{array}{l}\text { Resolution of mechanical } \\
\text { symptoms and pain }\end{array}$ \\
\hline 3 & 12.5 & L MFC & No & L knee arthroscopy only & $\begin{array}{l}\text { Resolution of mechanical } \\
\text { symptoms and pain }\end{array}$ \\
\hline 5 & 9.6 & R MFC & No & $\mathrm{R}$ knee debridement & $\begin{array}{l}\text { Resolution of mechanical } \\
\text { symptoms and pain }\end{array}$ \\
\hline $6^{*}$ & 10.4 & R MFC & No & None & No symptom progression \\
\hline 7 & 10.6 & $\begin{array}{l}\mathrm{R} \text { medial inferior } \\
\text { patella }\end{array}$ & $\begin{array}{l}\text { Fall on R knee } \\
\text { while skating }\end{array}$ & $\mathrm{R}$ knee debridement & $\begin{array}{l}\text { Resolution of mechanical } \\
\text { symptoms, ongoing pain }\end{array}$ \\
\hline
\end{tabular}

* OCD lesion present at the time of JIA diagnosis. OCD: osteochondritis dissecans; JIA: juvenile idiopathic arthritis; L: left; LFC: lateral femoral condyle; MFC: medial femoral condyle; R: right; MRI: magnetic resonance imaging.

better characterize the contribution of these factors to the development of OCD lesions in patients with JIA.

BRADLEY C. JACKSON 1 , MD, MSc; DEBRA L. BARTLEY, MD ROBERTA A. BERARD (D, MD, MSc, Department of Paediatrics, Children's Hospital, London Health Sciences Centre, London, Ontario, Canada. Address correspondence to Dr. R.A. Berard, Department of Paediatrics, 800 Commissioners Road E, London, Ontario N6A 5W9, Canada.

E-mail: Roberta.berard@1hsc.on.ca

\section{REFERENCES}

1. Bray CC, Watson ST. Current review of juvenile osteochondritis dissecans of the knee. Curr Orthop Pract 2015;26:466-74.

2. Kessler JI, Nikizad H, Shea KG, Jacobs JC, Bebchuk JD, Weiss JM. The demographics and epidemiology of osteochondritis dissecans of the knee in children and adolescents. Am J Sports Med 2014;42:320-6.

3. Lindén B. The incidence of osteochondritis dissecans in the condyles of the femur. Acta Orthop Scand 1976;47:664-7.

4. Weiss JM, Nikizad H, Shea KG, Gyurdzhyan S, Jacobs JC, Cannamela PC, et al. The incidence of surgery in osteochondritis dissecans in children and adolescents. Orthop J Sport Med 2016;4:2325967116635515.

5. König F. The classic: on loose bodies in the joint [translated from German]. Clin Orthop Relat Res 2013;471:1107-15.

6. Accadbled F, Vial J, Sales de Gauzy J. Osteochondritis dissecans of the knee. Orthop Traumatol Surg Res 2018;104:S97-105.

7. Kröger L, Piippo-Savolainen E, Tyrväinen E, Penttilä P, Kröger H. Osteochondral lesions in children with juvenile idiopathic arthritis. Pediatr Rheumatol Online J 2013;11:18.

8. Kubo H, Oommen PT, Hufeland M, Heusch P, Laws HJ, Krauspe R, et al. Osteochondritis dissecans shows a severe course and poor outcome in patients with juvenile idiopathic arthritis: a matched pair study of 22 cases. Rheumatol Int 2018;38:1705-12.

9. Prakken B, Albani S, Martini A. Juvenile idiopathic arthritis. Lancet 2011;377:2138-49.

10. Wernecke C, Braun HJ, Dragoo JL. The effect of intra-articular corticosteroids on articular cartilage: a systematic review. Orthop J Sport Med 2015;3:2325967115581163.

First Release January 15 2020; J Rheumatol 2020;47:3; doi:10.3899/jrheum.190731 